\title{
Creative, embodied practices, and the potentialities for sustainability transformations
}

\author{
Julia Bentz ${ }^{1,2}$ ( Letícia do Carmo ${ }^{3} \cdot$ Nicole Schafenacker $^{4} \cdot$ Jörn Schirok ${ }^{5} \cdot$ Sara Dal Corso $^{6}$
}

Received: 15 September 2020 / Accepted: 1 July 2021 / Published online: 22 July 2021

(c) The Author(s) 2021, corrected publication 2021

\begin{abstract}
This paper argues for an integrative approach to sustainability transformations, one that reconnects body and mind, that fuses art and science and that integrates diverse forms of knowledge in an open, collaborative and creative way. It responds to scholarship emphasizing the importance of connecting disparate ways of knowing, including scientific, artistic, embodied and local knowledges to better understand environmental change and to foster community resilience and engagement. This paper draws on the experience of an arts-based project in Lisbon, Portugal, and explores embodied and performative practices and their potential for climate change transformations. It puts forward and enlivens an example, where such forms of engaging communities can provide new insight into how equitable, just and sustainable transformations can come about. The process involved a series of interactive workshops with diverse arts-based methods and embodied practices to create performative material. From this process, a space emerged for the creation of meaning about climate change. Three key elements stood out in this process as being potentially important for the emergence of meaning-making and for understanding the impact of the project: the use of metaphors, embedding the project locally, and the use of creative, embodied practices. This furthers research, suggesting that the arts can play a critical role in engaging people with new perspectives on climate change and sustainability issues by offering opportunities for critical reflection and providing spaces for creative imagination and experimentation. Such processes may be important for contributing to the changes needed to realize transformations to sustainability.
\end{abstract}

Keywords Climate change $\cdot$ Experiential learning $\cdot$ Arts-based approaches $\cdot$ Art and climate $\cdot$ Inspiration $\cdot$ Meaningmaking $\cdot$ Embodiment $\cdot$ Imagination

Sara Dal Corso: Independent artist.

Handled by Karen O’Brien, University of Oslo, Norway.

Julia Bentz

juliabentz@gmail.com

1 CICS.NOVA Interdisciplinary Centre of Social Sciences, University Nova Lisboa, Colégio Almada Negreiros, Campus de Campolide, 1070-312 Lisbon, Portugal

2 Centre for Ecology, Evolution and Environmental Changes (ce3c), Faculty of Sciences, University of Lisbon, Campo Grande, Building C1, 4th floor, room 38, 1749-016 Lisbon, Portugal

3 Centro de Comunicação e Representação Espacial (CCRE) of Centro de Estudos de Arquitectura e Urbanismo (CEAU), Faculdade de Arquitectura da Universidade do Porto (FAUP), Via Panorâmica, S/N, 4150-564 Porto, Portugal
4 Health Arts Research Centre, University of Northern British Columbia, Room 9-380 Dr. Donald R. Rix Northern Health Sciences Centre, University of Northern British Columbia, 3333 University Way, Prince George, BC V2N 4Z9, Canada

5 Institute of Geography, Osnabrück University, 49069 Osnabrück, Germany

6 Lisbon, Portugal 


\section{Introduction}

At a time when the awareness of humanity's impact on the global environment has become part of the mainstream discourse radical, transformative approaches to climate change are increasingly being considered for their potential to create bold solution spaces. While the predicted consequences of climate change for our social, economic, political, institutional, and cultural worlds are still in the process of unfolding, the questions about the manner of how we transform are more important than ever. Critically inquiring into how we change and transform involves asking questions such as: what kind of future and co-living do we desire in our communities? How can we engage with climate change in a way that fosters agency and hope? What imaginative and collaborative forms of community engagement are useful in achieving this? Who or what drives these processes of transformation and what or whom is being transformed?

Transformation as a concept and practice has been approached from many different angles, as shown by the growing body of research from the natural and social sciences and humanities (Feola 2015). Recognizing the diversity of perspectives on transformation, the concept can be broadly characterized as "significant changes in form, structure and/or meaning-making" (O'Brien 2018). It can further be understood as a psycho-social process that uncovers the human potential to commit, care, and effect change for a better life, or an internal shift that alters the way one experiences and relates to oneself, others, and the world (Schlitz et al. 2010; Sharma 2007). In climate change research and practice, transformation is often seen as an approach that focuses on changing societal systems, structures, and relationships, which are seen as the root causes of unsustainability and climate change (Kates et al. 2012; O'Brien 2012). While the concept of transformation has moved into high policy forums, such as the UN, the IPBES, and the IPCC, inquiries into the manner and the how of transformation are still emerging, yet vital.

There is a growing recognition that the social sciences, humanities, and the arts have much to offer in the quest to develop sustainable transformations (Castree et al. 2014; Galafassi et al. 2018; Heras and Tàbara 2014). The humanities and the arts can both educate people about climate change and actively engage them in transformative processes (Bentz 2020; Bentz and O'Brien 2019). Recognizing the inseparability between the body and mind, the humanities and the arts can connect us with the innate knowledge that our senses reveal about an ever-changing world. Currently, most approaches to climate change education do not support the integration of different ways of knowing; in fact, it is rather the opposite (Leichenko and O'Brien 2020; Siegner and Stapert 2019). Many educational strategies tend to rely heavily on cognitive and passively transmissive forms of knowledge transfer, with limited attention to embodied and experiential techniques (Chabay 2020; Leichenko and O'Brien 2020; Sterling and Orr 2001).

Science communication also tends to be oriented toward the mindset that cognitive processes are separate from our bodies, and even further disconnected from the material and natural world (Weber 2013). This has widespread consequences, particularly for community engagement in sustainability initiatives. For example, the commonly held idea of body-mind duality has perpetuated a siloed way of thinking and approaching complex problems, often resulting in the search for single "solutions" (Weber 2013). Research has pointed to the need to better integrate cognitive, emotional, and embodied knowledges to generate a plurality of solutions and equitable, enduring change (Bentz 2020; Sharma 2017).

One way to engage cognitive, emotional, and embodied knowledges is through arts practices. Art can bridge knowledge systems and ways of knowing to enact social-ecological change (Rathwell and Armitage 2016). The growing interest in art as a form of inquiry and engagement in sustainability transformations may be due to its tremendous potential to challenge our perceptions and to engage its audience in a felt experience of transformation (Bentz 2020; Burke et al. 2018; Galafassi et al. 2018; Heras and Tàbara 2014). It has the potential to evoke emotional and political responses from the viewer through aesthetically powerful means. Art can create fertile spaces for people to engage with complex topics such as climate change on a personal and emotional level, linking the issue to their own lives and communities.

This paper discusses the contribution of embodied and performative art practices to sustainability transformations. Specifically, we focus on a devised theatre project in Lisbon, Portugal, entitled Climate Odyssey. This transdisciplinary, performative project fused art and science to introduce new ways of looking at every day actions and interactions. Below, we present the project and discuss how dance and storytelling (among other forms) can lead to deeper understandings of climate change and have the potential to challenge cultural norms. We suggest that collaborative, creative, and experiential learning processes can contribute to new perspectives on both the problems and solutions associated with climate change.

\section{Background and overview}

To situate this research, we begin by drawing on background literature that engages the concept of embodiment as a way of knowing and discuss its relevance for sustainability 
transformation "embodiment". We then examine performative art forms as methods for meaning-making. We further explore how embodied art forms can create space for dynamic solutions to emerge, and specifically how learning through the body can be a way to engage the complexities of climate change. In "Implementation context", we describe our methodologies, as well as the local historical context for the project and how this informed our choice of methodologies. We then discuss the specific steps we took to carry out the project, and describe the rationale and approach to our data collection methods and analysis. These were informed by the context of the project and its implementation. In "Results and discussion", we present results and reflect on the impact of the creation and performance of Climate Odyssey. Finally, in the "conclusion", we offer insights on key learnings related to creative, embodied ways of engaging with sustainability and transformation. While we do not aim to provide absolute answers on the manner of transformation, nor a blueprint for performative arts-based approaches to climate change, we wish to shed light on the power of integrative and embodied approaches to inspire subtle, yet profound, individual changes in relating to sustainability transformations.

\section{Embodiment as a way of knowing}

Embodied art forms, such as dance and theatre, offer powerful means to draw on our lived experiences and generate new insights and ways of meaning-making (Leavy 2015). For instance, role play or improvisation theater exercises can help people to appreciate more-than-human viewpoints in discussions where human-centric perspectives and anthropocentric values and needs tend to be prioritized (Pearson et al. 2018). The insights that are gained through such an embodied experience can lead to a process of examining one's own values and beliefs, and shed light on one's own biases and blind spots. Researching and being reflexive about one's own subjective truth may help to locate an intersubjective or shared truth. Furthermore, examining and questioning one's values and beliefs can provide understanding about the ways that they collectively shape our systems and structures, behaviors, and practices. Personal and subjective values, beliefs, and perceptions are directly related to political, economic, and socio-cultural structures that contribute to climate change (O'Brien and Wolf 2010). Therefore, critically reflecting on these values and beliefs and learning to know differently through the body may have profound implications on sustainability transformations.

Artistic and creative works are borne of embodied practices. Embodiment, which can be defined as a "generative state-generative of meaning, relationships, and an understanding of self" (O'Shea 2012, p. 35), plays an important role in creating knowledge. All experiences are ultimately embodied, since it is through the senses that we come to access knowledge (Wiebe and Snowber 2011). To this end, Pineau (1994) writes that "the active body learns in ways that are eminently more personal, applicable, critical and long-lasting than any other teaching method"' (Pineau 1994 cited in Hamera 2006, p. 403). Embodiment can be seen as the basis for how we make sense in the world.

In phenomenological embodiment literature, the body is conceptualized as having meaning in itself, as opposed to a container where meaning is stored. Experience, as phenomenologist Merleau-Ponty (2017) argues, exists between the mind and body; the body is the condition and context through which we have relations to objects and receive information. Even imagination is considered an embodied experience (Merleau-Ponty 2017). Following this idea of embodiment, we can use the body as a means to pose questions, connect with emotions and understand theoretical concepts. This way of knowing can challenge norms that are conditioned and often rendered invisible (Stinson 1995).

Consequently, it is through the senses and the body that we can see and experience ourselves and the world differently, and therefore, potentially alter our perceptions and behaviors. Embodied art forms, such as dance, performance and theater, offer a concrete means to enact this and thus contain transcendental, transformative potential (Leavy 2015; Wiebe and Snowber 2011). Engaging art as a means for enacting transformation even at a small scale may lead to emergent knowledges (Bentz 2020). We deliberately chose performative art forms as methodologies to guide us through new meaning-making and embodied experiences, to see and act differently on climate change and sustainability challenges.

\section{Performative art forms as methods of meaning-making}

Art can use novel metaphors, analogies, or narratives that speak to cognitive, emotional, embodied, and aesthetic knowledges and affect how we interpret and assign value to aspects of our life (Castree et al. 2014; Roosen et al. 2018). Rather than instrumentalizing art to communicate on behalf of other disciplines, art as its own method and methodology has tremendous capacity for communicating complex and nuanced subject matter (Bentz 2020; Hawkins 2016). Instead of pushing authoritative claims, art practices allow for multiple meanings to emerge. For example, a piece of visual art can be interpreted in different ways depending on the viewer as well as the context of viewing. Likewise, a theater performance can facilitate a means for the audience to experience a multitude of emotional responses to climate change by connecting empathetically with the characters on stage and their narratives. 
Theatre has always been a means of not only reflecting society back to itself, but also shaping it (Brecht and Willett 1964). As Boal (2000, p. 16) emphasizes "theater is a form of knowledge; it should and can be a means of transforming society". Since the 1970s, deliberately socially conscious forms such as Forum Theatre and devised theatre have flourished. Forum Theatre, a form of the Theatre of the Oppressed, reframes the traditional roles of spectators and actors as "spect-actors" that can passively watch or engage and influence the performance. The issues dealt with in Forum Theatre are often related to social justice with the aim to explore solutions to the oppression featured in the performance. Devised theatre, also referred to as collective creation, is a method of theatre-making in which the script or performance score originates from collaborative, often improvisatory work by the performing ensemble (Garcia 2013). This increases the level of agency and ownership each participant has in shaping the creation, and makes space to draw on their own lived experiences (Leavy 2015). In terms of process, the co-creative and embodied nature of these practices can strengthen participants' capacity for critical self-reflection and personal growth (Leavy 2015).

Using such theater methods can facilitate exploring reality from multiple angles. These can include empathizing with the different characters' points of view, reflecting on one's own similar lived experiences, imaging new possibilities, and critically engaging with the content as a whole, and more. For instance, building on the tradition of Boal's (2000) Theatre of the Oppressed, Diamond (2008) views communities as living organisms in his approach to Forum Theatre. He draws on systems theory and demonstrates how performance can be used as creative interventions to interrupt cultural feedback loops. By 'playing out' different scenarios, Diamond activates the audience's capacity for thinking about solutions to 'wicked problems', such as suicide and the mental health crisis in North America. Part of theatre's effectiveness lies in the fact that performance can engage complexity in a way that feels real (Saldaña 2011). By viewing emotionally or culturally 'loaded' content through a creative lens, both the participants and the audience can arrive at new insight. Boal claims that theater is a highly effective political weapon that can educate, inform, and move people to action (Boal 1998, 2000). More than a communication tool to engage matters in an aesthetic and attractive and accessible ways, art can facilitate experiential forms of questioning, (re)learning and thus space for dynamic solutions to emerge.

In this paper, we build on the ideas of socially engaged and co-creative forms of theater to explore transformation from multiple angles and engage in the complexities of climate change through embodied art forms. We incorporate insights on emotional, embodied, and aesthetic knowledges to question how we see and act on climate change and sustainability challenges.

\section{Methodology}

\section{Implementation context}

This research explores embodied art and performative practices and their potential to contribute to sustainability transformations. Our devised theatre project, Climate Odyssey, serves as a case study for this research. This project integrated a set of mixed methods that aimed to provide an inspiring learning experience on climate change and sustainability transformations and to co-create a performance with the project participants that was performed in May 2019 (Table 1).

The process was led and facilitated by a sustainability scientist (JB) and a performance artist and choreographer (SDC). It was further supported by an urban sociologist (LDC) and a human geography masters student (JS). The form we chose was devised theatre, which begins without a script. In devised theatre, the script develops through a series of improvisations and collaborations carried out by the ensemble (Garcia 2013). In contrast with more conventional theater practices that work with predefined scripts, co-creative methods may have a greater potential to create new meanings and may increase the participants' ownership of the play and regarding the topic of engagement (Norris 2000).

Climate Odyssey was performed in the neighborhood of Telheiras, located in the Northern part of Lisbon, Portugal. Since 1960s, Telheiras has experienced a period of relatively fast urbanization, losing most of its former farmable lands to residential buildings. Most recently, it has become the site of several pioneer community initiatives focusing on ecology, intergenerational knowledge, and solidarity. Several initiatives have responded to the growing interest in sustainable mobility and green areas. Telheiras is also a part of the pilot cases of the Municipalities in Transition, a network of transition initiatives that are committed to sustainable, systemic change (Municipalities in Transition 2020).

The Climate Odyssey process began with an open call inviting the members of the local (Telheiras) and municipal (Lisbon) community to join the project as self-nominated participants. The project was centered around a series of 12 weekly interactive art-and-science workshops between February and May 2019. In these workshops, Climate Odyssey was developed based on the original contributions of the participants. These 90-min workshops took place on weekdays in the afternoon in a community building. Fifteen regular participants (eleven women and four men), ranging between 22 and 75 years old, attended the sessions. Several 
Table 1 Methodological approach of Climate Odyssey

\begin{tabular}{|c|c|c|}
\hline Project objectives and key themes & Methods & Sources and instructions \\
\hline 1. Generate inspiration through metaphors & $\begin{array}{l}\text { Circle of objects a) } \\
\text { Photovoice } \\
\text { Embodying climate change images b) } \\
\text { Inspiration exercise: Science Fiction and } \\
\text { hybrid beings c) } \\
\text { Body practice and theater exercises f) }\end{array}$ & $\begin{array}{l}\text { (a) Exercise from Pearson et al. (2018) } \\
\text { (b) Participants work in groups with self- } \\
\text { researched/selected images by embodying } \\
\text { them } \\
\text { (c) Creative imagination exercise based on sci- } \\
\text { ence fiction images and stories }\end{array}$ \\
\hline $\begin{array}{l}\text { 2. Discover local transformations and inter- } \\
\text { relations }\end{array}$ & $\begin{array}{l}\text { Answer with your feet d) } \\
\text { Storytelling exercise: Timeline of transforma- } \\
\text { tion a) } \\
\text { Affective maps e) } \\
\text { Photovoice } \\
\text { Body practice and theater exercises f) }\end{array}$ & $\begin{array}{l}\text { (d) Ice breaker exercise from Red Cross Red } \\
\text { Crescent Climate Centre Facilitation Tech- } \\
\text { niques and Learning Games, } 2020 \\
\text { (e) Participants work in groups and indicate in } \\
\text { a map personally important places in their } \\
\text { neighborhood }\end{array}$ \\
\hline 3. Co-create meaning about climate change & $\begin{array}{l}\text { Imagination exercise: Museum of Transforma- } \\
\text { tion g) } \\
\text { Storytelling exercise: Timeline of transforma- } \\
\text { tion a) } \\
\text { Learning game: Climate change challenge h) } \\
\text { Photovoice } \\
\text { Creative writing exercise: non-human stake- } \\
\text { holders a) } \\
\text { Embodying climate change images b) } \\
\text { Body practice and theater exercises f) }\end{array}$ & $\begin{array}{l}\text { (f) Variety of exercises for movement, body } \\
\text { awareness and presence } \\
\text { (g) A guided meditation transports participants } \\
\text { to the future (e.g. 2100) where they find a } \\
\text { museum that narrates the story of a transfor- } \\
\text { mation to a sustainable and equitable planet } \\
\text { between now and } 2100 \text {. Participants work in } \\
\text { groups and create a common image and story } \\
\text { that they share with the group } \\
\text { (h) Learning game from Y-adapt project } \\
\text { (RedCross Red Crescent Climate Centre et al. } \\
\text { 2020) }\end{array}$ \\
\hline
\end{tabular}

of the participants were retired or shift workers, and some younger participants were students or unemployed and were flexible to join afternoon sessions. Most of the participants had no previous experience in dance or theater. Because of this, fostering a safe space for creative risk-taking and growth was paramount. The date for the public performance was set a few months ahead and this informed the timeline of the process.

\section{Approach and rationale behind creating Climate Odyssey}

Using dance, movement, and storytelling, we grounded this work in the body. In the weekly workshops, movement practices comprised about half or more of the $90 \mathrm{~min}$ and included acting exercises (such as by Chekhov 2005), improvisational games, simple choreography designed to build ensemble, and the embodiment of images related to climate change. The exercises focused on creating awareness for different body parts and for the group as a whole. This exploratory approach to movement involved exercises for coordinating breath and movement, for discovering the interrelation between weight, space, and time, and for being in relation to other bodies 'on stage'. The participants were guided on this exploration of body and movement and practiced a routine of movements during the 3 months of the project. Different exercises were added each week that correlated with the theme of the workshop: e.g., exploring the qualities of movement inspired by nature, animals, or the elements or by abstract geometry; or creating relations between bodies in space through playing with pictures related to climate change and embodying them. Through these playful, creative exercises small vignettes, or scenes, emerged.

The interactive arts-based workshops were structured around key themes and objectives that we as facilitators identified as important. These were: inspirations through metaphors (1), discovering local transformations and interrelations (2), and co-creating meaning about climate change (3). These elements, the key themes and objectives, served as signposts for guiding the creative process in the workshops (Table 1). In the following subsections, we will explore these elements, the steps undertaken, and their role in shaping the creative process.

The Climate Odyssey workshops were designed to create inspiration through metaphor (1). Several arts-based exercises and methods (Table 1) used metaphors and images to inspire new perspectives on the subject matter. There is a need for new, generative and inspiring metaphors and narratives on climate change and transformation that go beyond fear-based messages and are capable of fostering hope and agency (O'Brien 2020). However, when engaging with transformation, it is not always clear what exactly needs to be transformed and why, or what consequences will be following a transformative process. Enacting transformation can be murky territory - it requires venturing into the unknown. This is where metaphor, image, and narrative may act as helpful guides. 
The central metaphor of our project was that of a journey of discovery - an odyssey. The metaphor of an odyssey has been used in narrative structures throughout literary and dramatic history to depict an arduous adventure, as well as an intellectual or spiritual quest. Our engagement with metaphor guided not only the creative process, but ultimately it shaped the structure of our performance in which the audience ventured through the neighborhood of Telheiras. In this way, content and form referenced one another. Rather than focusing solely on the dangers and catastrophic impacts of climate change, it aimed to draw out participants' capacity for transformative change. It provided an invitation to embark on an odyssey into the uncharted territory of our own individual and collective psyches in relation to climate change.

We prepared to enter into the territory of the 'unknown' as creative investigators of what the future may be. Our bedrock was the shared histories and interrelations between the project participants who all had some relation to the neighborhood of Telheiras (2). Our objective as facilitators was to creatively engage these shared histories and interrelations. A guiding question of our research was the interrelation between the community and the place and in relation to change. We used several arts-based methods to facilitate the sharing of the participants' own lived experiences and stories related to environmental change. For instance, some older participants shared stories about the catastrophic floods in Lisbon in 1967, which caused many deaths (Timeline of Transformation, Table1). These stories created the main thrust of the second scene in the performance (see Appendix 1). We then determined a trajectory of locations in the neighborhood where each scene was set. This trajectory, an odyssey itself, elicited local stories of change and transformation, making visible and exploring the various aspects (social, cultural, and environmental) of climate change.

Conceptualized as a transdisciplinary art-science-practice experiment, the workshops explored the relationship between community and change and, on a broader scale, the relationship between humans and nature. The creative source material included endangered species, climate fiction, historic events, utopian visions, and many others. These metaphors and inspirations were used to offer new perspectives on climate change and to discover personal meanings (3).

Research has sought to bring climate change 'near' and embed it more within local viewpoints or topics that are relevant for a specific audience to support a process where personal meaning is created (Hochachka 2019). During the workshops, several methods were applied to bring climate change near, including storytelling, embodiment exercises, and photovoice (Table 1). Throughout the creative process, we invited the participants to become researchers themselves and engage in their own meaning-making process about climate change and the actions they wished for their community and more globally.

\section{Data collection and analysis}

To shed light on the potential contribution of embodied and performative practices to sustainability transformations, we collected data in several moments of the project. At the first encounter participants filled out a short registration form, and then a feedback form at the last workshop after the performance. The registration and feedback forms assessed the participants' motivations and level of satisfaction with the project as well as evaluated specific methods. In addition, we used photovoice as a data collection method in which participants answer questions visually via their own photography (Wang and Burris 1997). It is a transformative means in itself and can prompt a reflective experience of meaning-making for participants (Masterson et al. 2018). We applied the method to initiate participants' reflections on their relationship to climate change and the neighborhood of Telheiras. The pictures the participants captured served as a starting point for the qualitative interviews that followed (Castleden et al. 2008; Wang and Burris 1997). These interviews were conducted during the last week of the project and explored what climate change meant to the participants, what their values were more generally, and how the project had affected their attitudes to sustainability and transformation. One year after the performance, participants were also asked to take part in a follow-up survey that was sent via email. The follow-up survey aimed to explore the longer lasting impressions and impacts of artsbased approaches and the project itself through open-ended questions. Of the 15 participants, 9 were interviewed and 12 responded to the feedback form and follow-up survey. The interviews were recorded and transcribed. The transcripts and responses to open-ended questions in the follow-up survey were then coded. Specific codes were assigned to the data using MaxQDA.

\section{Results and discussion}

The Climate Odyssey project intended to generate inspiration for transformative change through exploring local initiatives and the relationalities between a community and the natural world. Through this case study, we inquired into climate change through devised theatre, dance, and storytelling. We explored how embodied art forms can lead to a deeper understanding and connection to a topic that is commonly perceived as abstract and distant. In this section, we detail our process for creating Climate Odyssey and the impact of this process on the participants and discuss insights gained from this process. 


\section{Co-creating a performance}

Five scenes emerged from the workshops. This material was arranged in a collage-like structure, giving the odyssey an abstract form. Each scene was independent from the others and yet all of them drew on the overarching theme of climate change, offering different viewpoints, images, and narratives. As such, these created an overarching storyline. The scenes were enacted in five different locations along a pathway, following the logic of a journey of discovery. A "guide", played by one of the participant actors, led the audience on this odyssey to each of the five scenes that were located in public spaces within the neighborhood. The open-air settings were prepared with chairs for 30 spectators. To allow a larger audience to attend the performance, three consecutive showings were offered. The duration of the performance was around $80 \mathrm{~min}$ and was integrated within the program of a local festival.

Each of the five scenes grew out of a combination of devising exercises from the interactive workshops. For instance, the hybrid beings (Fig. 1) in Scene 1 were prompted by a creative writing exercise, in which participants wrote poetry from the perspective of endangered species (Non-human Stakeholders; Table 1). Offering an alternative to an anthropocentric view on climate change, the choreographed movements of the dancers illustrated the interrelationship and interconnectedness between humans and nature. Depicting the awakening of a single creature, the movements of its individual parts were shown to impact the whole of the being and vice versa through a choreographed sequence of a wave drawing lines against the wall behind the dancers in a harmonious 'chain' effect of movement (Fig. 1).
Then, as Scene 1 came to a close, the atmosphere began to change as the 'chain of connection' broke down and morphed into an image of survival and disconnection. The movements of the dancers were driven by the opposing forces of hope and desperation, control and rebellion, oppression, and subversion. The scene explored possible future scenarios in a warming world. It juxtaposed the specific impacts of climate change on a community as well as the community's resilience.

In contrast to the abstract and imaginative quality of Scene 1, Scene 2 explored concrete past and present impacts related to extreme weather events. Staged as a 'coffee table dialogue', the scene was created from a storytelling exercise, where participants were asked to share experiences that made them aware of a changing climate. A more traditional theatre style was adopted as the performers' individual memories of how they first came to notice the impacts of climate change were structured into dialogue (Fig. 2).

Scene 3 centered on the inner conflict between engaging in climate action and the personal struggle to believe that a single person can make a change. The scene developed out of a monologue written by one of the participants expressing doubt about his individual actions to address climate change (e.g., composting, shorter showers) knowing that other actions (e.g., buying a new smartphone) would level out his efforts. This scene brought forward the reality that facing climate change requires profound individual and systemic changes. This monologue was contrasted with another performer, a pregnant woman, dancing in the background suggesting the possibility of a rebirth of humanity. Scene 3 hinged on the juxtaposition between her dance and his words, between sadness and hope, rational thinking, and intuitive knowing. The woman's soft movements evoked the
Fig. 1 Scene 1, photo by Ana Isa Mourinho

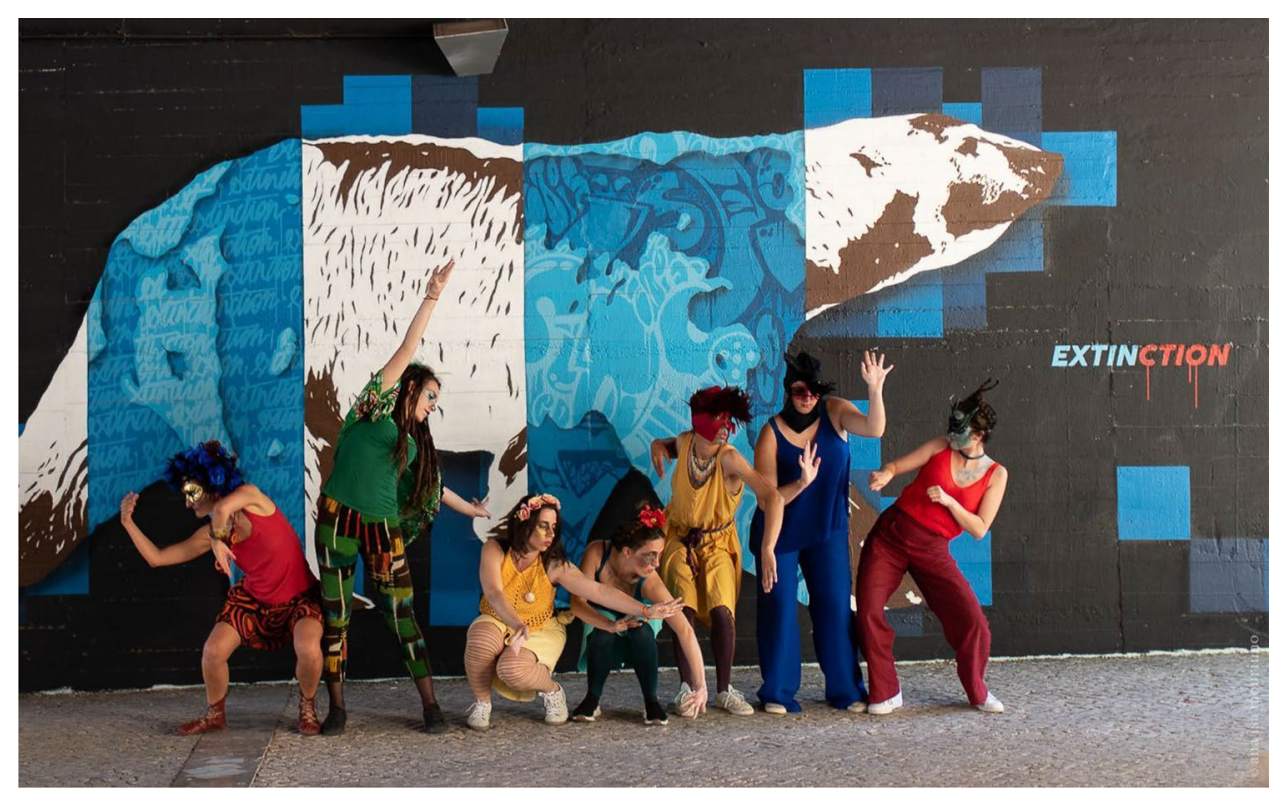


Fig. 2 Scene 3, photo by Ana Isa Mourinho

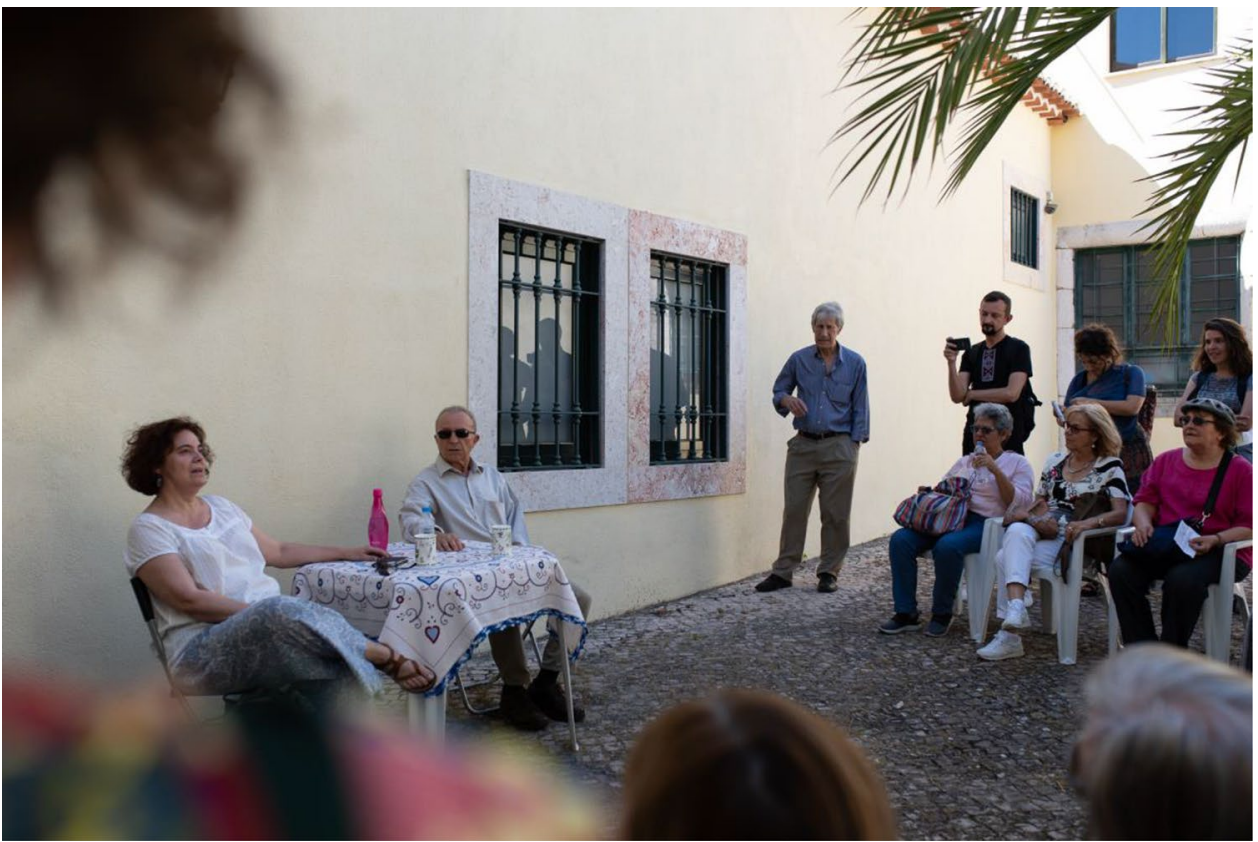

possibility of transformation and what is yet to come, contrasted with the technical language of measuring one's own impact expressed in the young man's monologue (Fig. 3).

In Scene 4, 'humanity' as a whole is depicted as being both responsible for climate change and as the victim of its impacts. The actors representing 'humanity' walk from one side to the other, representing a mass movement. From time to time, they stop to embody an image, a tableau, and then return to their walking state. These 'frozen pictures' drew on images collected by the participants as part of their individual research. The pictures depicted weather-related events (floods of Idaí, Mozambique, 2019; floods of Lisbon, 1967; fires of Pedrogão Grande, Portugal, 2017) that the participants considered important due their scale, impact, or symbolic value (Fig. 4).

In contrast to the dark tone of Scene 4, the final scene, Scene 5, ended the performance on a note of community building and connection. Set in a local green space this scene used music, specifically a drum circle, to foster the idea that resilience can be achieved with collaboration. Audience members were invited to become performers and take a participatory role in creating the final scene. Through
Fig. 3 Scene 3, photo by Ana Isa Mourinho

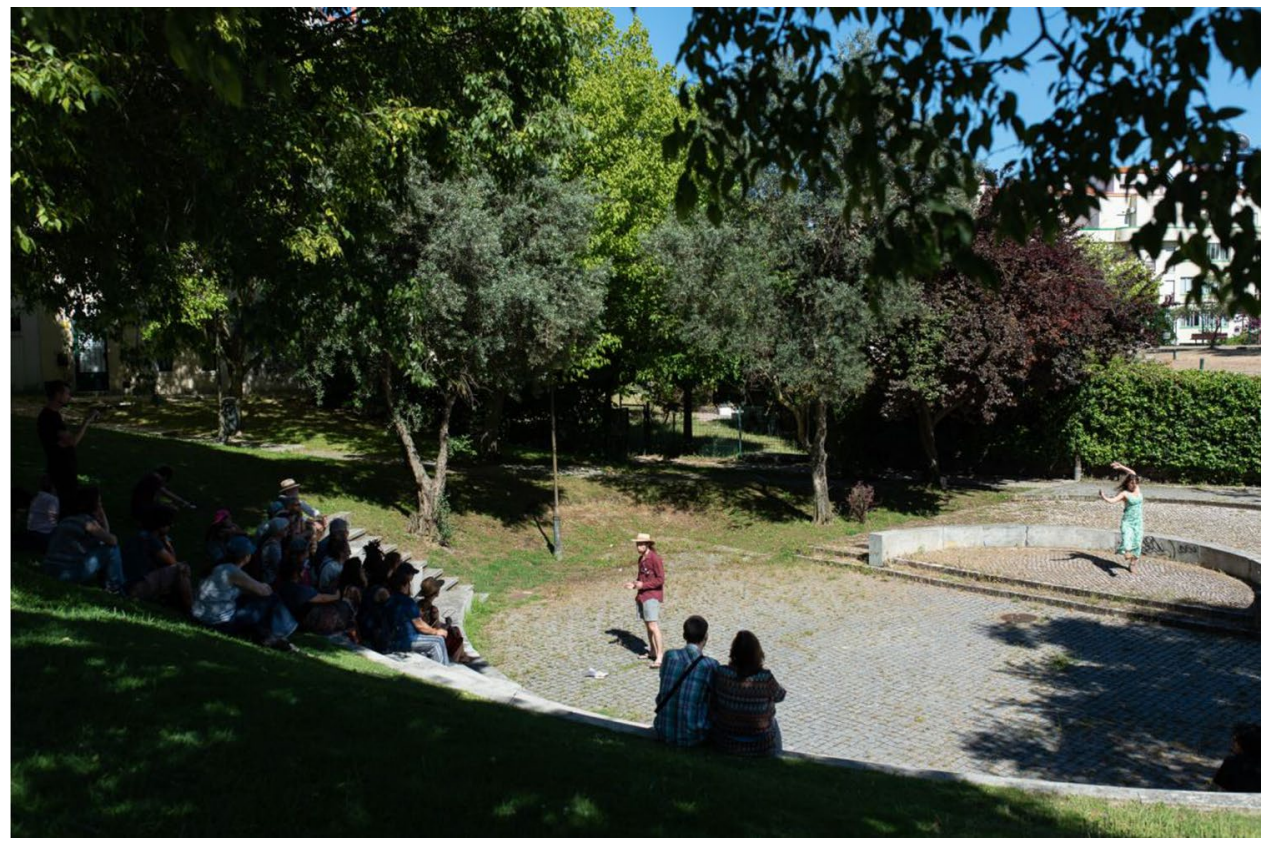


Fig. 4 Scene 4, photo by Ana Isa Mourinho

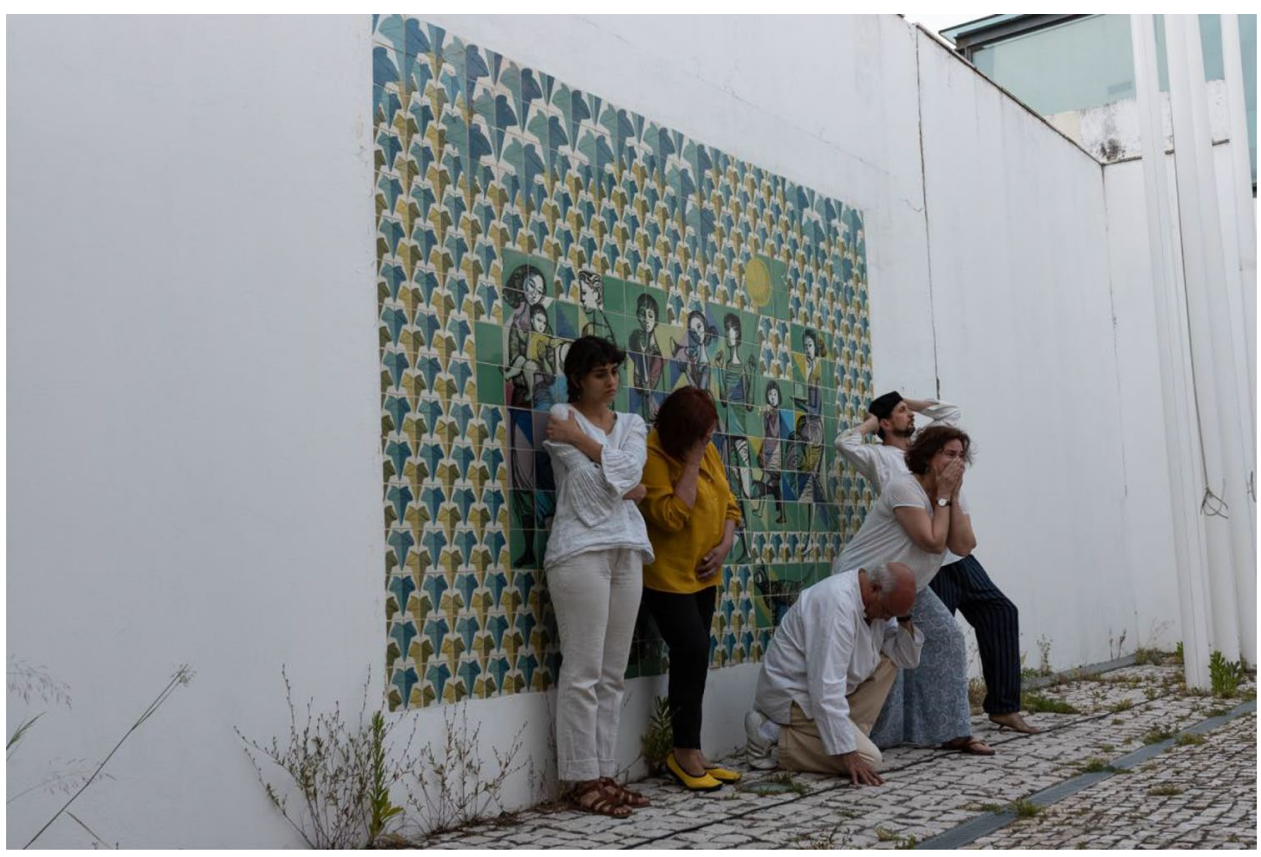

a series of exercises based on listening and repeating, they created the music for the final scene (Fig. 5). This process moved the attention toward the 'voice' of the whole of the group and spoke to the profound human need for belonging and the desire to feel in harmony in a group. The cocreative approach of the drum circle related to the capacity of individuals to act consciously as a whole. The final act of planting a tree together concluded the performance through a symbol of hope.

The Climate Odyssey performance moved the audience to tears and laughter and was a powerful way to culminate this research. The positive reception of the performance was in part due to the commitment of the participants to the workshops and the creative process as a whole. Throughout the regular meetings, individuals took the risk to share their experiences and different ways of knowing. The group embraced this vulnerability and showed one another that these experiences were of value. From this, a sense of community emerged among the group. This could be seen in the increasing chatter among the participants at the beginning and after each workshop session, the hugging and kisses to greet and say good-bye, and in the overall supportive
Fig. 5 Scene 5, photo by Ana Isa Mourinho

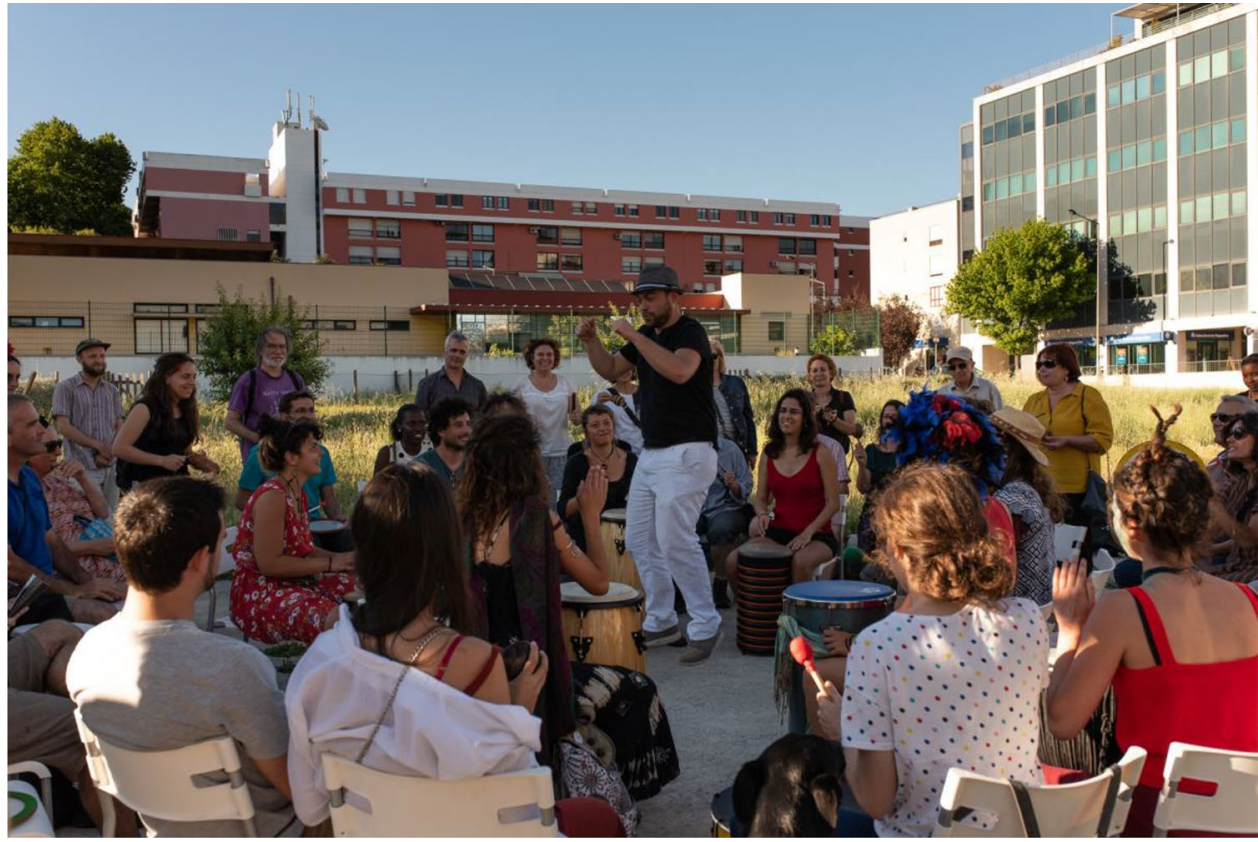


atmosphere during the sessions. Through fostering a safe space and a foundation of trust, participants were supported in taking personal and creative risks. This allowed each participant to overcome personal obstacles as performercreators and to develop confidence both as individuals and as an ensemble. Taking part in the creation and performance of Climate Odyssey was an accomplishment for many of them. The overwhelmingly positive reaction of the audience reinforced this sense of achievement. It also empowered participants to see the value of taking action through creative means.

\section{Exploring the transformative potential of embodied art forms}

How do we determine if an action, such as creating Climate Odyssey, had a transformative impact? We will argue here that transformation may be made up of several subtle, yet profound, individual changes. Recognizing the challenges related to measuring these impacts, this article set out to explore the potential of performative arts practices for contributing to equitable and sustainable transformations. There is a knowledge-action gap for many people when it comes to moving beyond abstract notions of climate change and instead relating to sustainability in a way that empowers personal agency. Drawing on personal, embodied knowledges through art practices may be a way to address this gap and to create innovative solution spaces. Acknowledging the power of emotions and other ways of knowing, we used art to help us reevaluate our daily actions, challenge cultural norms, and realize the interconnection between body and mind.

The dataset, including qualitative interviews, feedback forms, and the survey a year after the performance, provided some insight on the new meanings and perspectives the project generated among the participants. Two themes that are particularly relevant for sustainability transformations were identified through this data. These were: a new sense of agency, and a different relationship to the topic of climate change. The deeper sense of personal agency may have emerged through the reflective exercises that were built into the project. Over the course of several months, participants and we as facilitators explored a set of questions around the relationships to self, others and nature and reflected upon one's role in contributing to just and sustainable change. Possibly, this led to a greater sense of agency as the following quote from a participant interview suggests: "I think that the whole process of the [Climate] Odyssey workshops will help me to put things into practice. [...] I mean it made me think deeper about my own role, or what I could do as an individual, a lot deeper than I did before. [...] I think my experience will influence other people who did not participate in the workshop also." This finding may relate to Freire's insight that "responsibility cannot be acquired intellectually, but only through experience" (Freire 1974, p. 13) and highlights the importance of experiential, embodied learning to develop empowerment and agency.

Furthermore, this sense of agency extended to a deeper appreciation for building relationships and teamwork in community. In reflecting 1 year after the performance, the co-creative process was one of the aspects that stayed most strongly with the participants. In the follow-up survey, one participant wrote: "The greatest learning was the experience provided by the interaction with very different people. An almost ad-hoc team produced something greater than the sum of the parts." This supports the premise that such co-creative processes featuring different actors have deeply inspiring and empowering effects. The co-creative process showed that, despite the challenge and messiness of engaging complexity and the unknown, it is possible to produce impactful, and even aesthetically satisfying work as a group.

Art's ability to create agency among people can be attributed to its potential to provide moments of learning and inspiration (Bentz and O'Brien 2019). This naturally relates to the second theme we recognized in our data: the development of a different relationship to climate change by participants. One participant emphasized that the framing and metaphor of climate change transformations as a journey of discovery led to new perspectives: "For me it was a way to have a deeper understanding of climate change and to have also different solutions in mind. I would say, more collective ones. I think that I also became more optimistic. Because I was really pessimistic about it in the beginning." This quote speaks to findings that the transformative potential of art is related to its capacity to attend to and transform emotions, creating positive emotions such as hope, responsibility, care, and solidarity (Ryan 2016). It can then activate the desire to engage and contribute to alternative futures. It may create a force and a desire to help close the gap between what we know and what we do about climate change (Galafassi et al. 2018).

Furthermore, engaging with art can help people to see things from new angles through its ability to "slow down" thinking (Stengers 2005). It is potentially in this "slowing down" that creative processes facilitate that participants have the opportunity to question their frames of reference and practice reflexivity. For instance, the photovoice exercise was an important tool within this process, as the following interview quote demonstrates: "I think it [the photovoice exercise] made you go a lot deeper into the questions [...]. If I just had to write the answers, I would have probably answered all those questions in two minutes. But the challenge was to take a picture to answer that question, so that actually made me think about it." The shift in perspective that is achieved through this exercise hinges on its openness, which allows for free thinking without expectation-and therefore the emergence of new knowledge. 
Overall, the follow-up survey a year later showed that Climate Odyssey's emphasis on experiential and embodied learning facilitated an atmosphere of "community, oneness, growth, path to self-awareness and awareness of the world" among the participants, and a sense of "becoming aware by experiencing the whole being, through the physical, emotional, mental and in the collective" (a participant's quotes in follow-up survey). This supports the importance of dissolving the Cartesian belief of a mind body divide and, instead, engaging the innate knowledge that our senses perceive and hold when we address complex problems such as climate change. It provides insight into the potential of embodied art forms to facilitate spaces in which local transformations can take place.

\section{Limitations}

In retrospect, a potential limitation of our approach was a limited synergistic collaboration between the community and the local authorities. We believe that there is a need to closely collaborate with local authorities in a synergistic way to produce sustained impact and to shift systems. System shifts occur when the values and principles of two entities are aligned and when both are committed to sustainable change (Sharma 2017). We believe that, in the future, a stronger alignment can be fostered through value-based conversations focusing on the common ground between the project and the supporting institutions. As with many sustainability projects, there is a risk that the creative impulse may be lost without a supportive structure to advance the insights and energy generated by the project. Recognizing the need to nurture the newly created sense of community and agency, we planted three trees in the neighborhood that are native to the Iberian Peninsula, one at the end of each performance. This was an attempt to create a symbol for the generated sense of responsibility and care that required continuous commitment from the community members.

\section{Conclusion}

This paper argues for an integrative approach to sustainability transformations. It seeks to embrace the body-mind as one, to fuse art and science, and to integrate diverse forms of knowledge in an open, collaborative, and creative way. Through the co-creative, embodied art-science-practice learning approach of the Climate Odyssey project, we have illustrated the potential of such forms for engaging communities and evoking insight into the 'how' of equitable, just and sustainable transformations.

While we do not provide absolute answers on the manner of transformation, nor a blueprint for performative approaches to sustainability, we share some insight on the power of integrative and embodied approaches to climate change transformation. There is a need for further research on embedded and embodied forms of learning and engaging climate change in community, specifically the longer term impacts of arts-based learning approaches. Yet, three insights stand out from this study as being potentially important for understanding the impact of the project: the use of metaphors, embedding the project locally, and the use of several creative-embodied practices.

Engaging in sustainability transformation through metaphor represented an effective aspect of the project that contributed to new perspectives on climate change transformation and one's role in relation to it. The metaphor of the odyssey set the tone for an open-ended inquiry related to the various individual and collective aspects of climate change. Metaphors can help exploring processes of change and transformation from different angles, for instance, by offering alternative framings to the usual emphasis on disaster in climate narratives. Metaphors and images can also inspire the participants, such as the hybrid human-animal beings in our case, which allowed performers to inquire into the potential unfolding of different scenarios of transformative change through play and embodiment.

Embedding the project and process locally through participants' stories helps to bring climate change near, to create meaning and foster connection among participants. Exploring and understanding local complexities 'on the ground' makes the impact of such work more tangible. By centering the lived experience and expertise of participants from Telheiras, an opportunity was formed to establish an atmosphere of mutual learning and knowledge inclusion. Through the open-ended nature of the process, both participants and facilitators embarked on a sort of odyssey that centered creative and collaborative problemsolving and learning.

Most importantly through the open-ended process, drawing from many creative and embodied practices, a space can emerge for meaning about climate change to be cocreated. Experiential exercises such as photovoice, dance and movement, role play, poetry writing, and the creation of a performance help exploring what (climate) change and transformation means for us individually and collectively. These practices provide spaces for creative imagination and experimentation. This makes embodied art forms powerful tools for exploring climate change and transformations to sustainability in a way that creates hope, inspiration, and agency.

Acknowledgements We would like to thank the participants of the Climate Odyssey who contributed with their authenticity, care, and openness to the success of this project. We would like to express gratitude to Luis Keel Pereira of Centro de Convergência de Telheiras for creating the crucial connections locally, to Hugo Wittmann for facilitating the Drum Circle, to Florian Ulm for facilitating the tree plantings, 
and to Ana Isa Mourinho taking pictures of the public performance. We are grateful for constructive feedback and excellent edits of Morgan Scoville-Simonds, Karen O'Brien, Irmelin Gram-Hanssen, Danielle Huffaker, and the two anonymous reviewers. This project was financed by the Portuguese Foundation for Science and Technology (reference SFRH/BPD/115656/2016), the local perish Junta de Freguesia do Lumiar, and by the University of Osnabrück. This publication was financed by the Norwegian Research Council in connection with the AdaptationCONNECTS project, funding number 250434.

Open Access This article is licensed under a Creative Commons Attribution 4.0 International License, which permits use, sharing, adaptation, distribution and reproduction in any medium or format, as long as you give appropriate credit to the original author(s) and the source, provide a link to the Creative Commons licence, and indicate if changes were made. The images or other third party material in this article are included in the article's Creative Commons licence, unless indicated otherwise in a credit line to the material. If material is not included in the article's Creative Commons licence and your intended use is not permitted by statutory regulation or exceeds the permitted use, you will need to obtain permission directly from the copyright holder. To view a copy of this licence, visit http://creativecommons.org/licenses/by/4.0/.

\section{References}

Bentz J (2020) Learning about climate change in, with and through art. Clim Change. https://doi.org/10.1007/s10584-020-02804-4

Bentz J, O'Brien K (2019) ART FOR CHANGE: transformative learning and youth empowerment in a changing climate. Elem Sci Anthr 7(1):52. https://doi.org/10.1525/elementa.390

Boal A (1998) Legislative theatre: using performance to make politics. Routledge, London

Boal A (2000) Theater of the oppressed. Pluto Press, London

Brecht B, Willett J (1964) Brecht on theatre: the development of an aesthetic. Hill and Wang, New York

Burke M, Ockwell D, Whitmarsh L (2018) Participatory arts and affective engagement with climate change: the missing link in achieving climate compatible behaviour change? Glob Environ Change 49:95-105. https://doi.org/10.1016/j.gloenvcha.2018.02.007

Castleden H, Garvin T, Nation H-a-A (2008) Modifying photovoice for community-based participatory indigenous research. Soc Sci Med (1982) 66(6):1393-1405. https://doi.org/10.1016/j.socsc imed.2007.11.030

Castree N, Adams WM, Barry J, Brockington D, Büscher B, Corbera E, Demeritt D, Duffy R, Neves K, Newell P, Pellizzoni L, Rigby K, Robbins P, Robin L, Rose DB, Ross A, Schlosberg D, Sörlin S, West P, Wynne B (2014) Changing the intellectual climate. https:// www.repository.cam.ac.uk/handle/1810/247152

Chabay I (2020) Vision, identity, and collective behavior change on pathways to sustainable futures. Evol Inst Econ Rev 17(1):151165. https://doi.org/10.1007/s40844-019-00151-3

Chekhov M (2005) On theatre and the art of acting. Applause Theatre Book Publishers. https://www.goodreads.com/book/show/21432 301-michael-chekhov

Diamond D (2008) Theatre for living: the art and science of community-based dialogue. Trafford Publishing, Bloomington

Feola G (2015) Societal transformation in response to global environmental change: a review of emerging concepts. Ambio 44(5):376390. https://doi.org/10.1007/s13280-014-0582-z
Freire P (1974) Education for critical consciousness. Bloomsbury Academic, New York

Galafassi D, Kagan S, Milkoreit M, Heras M, Bilodeau C, Bourke SJ, Merrie A, Guerrero L, Pétursdóttir G, Tàbara JD (2018) 'Raising the temperature': the arts on a warming planet. Curr Opin Environ Sustain 31:71-79. https://doi.org/10.1016/j.cosust.2017.12.010

Garcia V (2013) The paradox of devised theater on the twenty-first century stage. HowlRound Theatre Commons. https://howlround. $\mathrm{com} /$ paradox-devised-theater-twenty-first-century-stage

Hamera JA (2006) The SAGE handbook of performance studies. SAGE, Thousand Oaks

Hawkins H (2016) Creativity, 1st edn. Routledge, London

Heras M, Tàbara JD (2014) Let's play transformations! Performative methods for sustainability. Sustain Sci 9(3):379-398. https://doi. org/10.1007/s11625-014-0245-9

Hochachka G (2019) On matryoshkas and meaning-making: Understanding the plasticity of climate change. Glob Environ Change 57:101917. https://doi.org/10.1016/j.gloenvcha.2019.05.001

Kates RW, Travis WR, Wilbanks TJ (2012) Transformational adaptation when incremental adaptations to climate change are insufficient. In: Proceedings of the National Academy of Sciences, vol 109. No 19 pp 7156-7161. https://doi.org/10.1073/pnas.11155 21109

Leavy P (2015) Method meets art: arts-based research practice, 2nd edn. Guilford Publications, New York

Leichenko R, O'Brien K (2020) Teaching climate change in the anthropocene: an integrative approach. Anthropocene 30:100241. https://doi.org/10.1016/j.ancene.2020.100241

Masterson VA, Mahajan SL, Tengö M (2018) Photovoice for mobilizing insights on human well-being in complex social-ecological systems: case studies from Kenya and South Africa. Ecol Soc 23(3):13. https://doi.org/10.2307/26799137

Merleau-Ponty M (2017) Phenomenology of perception. Andesite Press, London

Municipalities in Transition (2020) Parceria Local de TelheirasMunicipalities in Transition. https://municipalitiesintransition. org/harvesting/parceria-local-de-telheiras/

Norris J (2000) Drama as research: realizing the potential of drama in education as a research methodology. Youth Theatre J 14(1):40 51. https://doi.org/10.1080/08929092.2000.10012516

O'Brien (2012) Global environmental change II: from adaptation to deliberate transformation. Progr Human Geograph 36(5):667676. https://doi.org/10.1177/0309132511425767

O'Brien K (2018) Is the $1.5{ }^{\circ} \mathrm{C}$ target possible? Exploring the three spheres of transformation. Curr Opin Environ Sustain 31:153160. https://doi.org/10.1016/j.cosust.2018.04.010

O’Brien K (2020) You Matter More Than You Think-Quantum Social Change in Response to a World in Crisis (draft for discussion). Adaptation CONNECTS, University of Oslo, Norway. https:// drive.google.com/file/d/10VAZqk0WNoA5nYSKGMGFAkRB yzv6eomg/view?usp=embed_facebook. Accessed Sept 2020

O'Brien KL, Wolf J (2010) A values-based approach to vulnerability and adaptation to climate change. Wiley Interdiscip Rev Clim Change 1(2):232-242. https://doi.org/10.1002/wcc.30

O'Shea M (2012) Embodying and performing sustainability [UBC, Vancouver]. https://open.library.ubc.ca/cIRcle/collections/ubcth eses/24/items/1.0073124

Pearson KR, Bäckman M, Grenni S, Moriggi A, Pisters S, de Vrieze A (2018) Arts-based methods for transformative engagement: A toolkit (p.). SUSPLACE. http://library.wur.nl/WebQuery/wurpu bs $/ 533984$ 
Rathwell K, Armitage D (2016) Art and artistic processes bridge knowledge systems about social-ecological change: an empirical examination with Inuit artists from Nunavut, Canada. Ecol Soc. https://doi.org/10.5751/ES-08369-210221

RedCross Red Crescent Climate Centre, Engagement Lab at Emerson College, Philippines Red Cross, \& PLAN Philippines (2020) Y-Adapt Curriculum; Facilitation Guide.pdf. Y-Adapt Curriculum; Facilitation Guide. Retrieved November 12, 2020, from https://www.climatecentre.org/downloads/files/Y-Adapt\%20Cur riculum $\% 3$ B $\% 20$ Facilitation $\% 20$ Guide $\% 281 \% 29$.pdf. Accessed Sept 2020

Red Cross Red Crescent Climate Centre facilitation techniques and learning games (2020) https://www.climatecentre.org/resourcesand-games/games/17/answer-with-your-feet. Accessed Sept 2020

Roosen LJ, Klöckner CA, Swim JK (2018) Visual art as a way to communicate climate change: a psychological perspective on climate change-related art. World Art 8(1):85-110. https://doi.org/10. $1080 / 21500894.2017 .1375002$

Ryan K (2016) Incorporating emotional geography into climate change research: a case study in Londonderry, Vermont, USA. Emot Space Soc 19:5-12. https://doi.org/10.1016/j.emospa.2016.02.006

Saldaña J (2011) Ethnotheatre: research from page to stage-qualitative inquiry and social justice. Left Coast Press, Walnut Creek

Schlitz MM, Vieten C, Miller EM (2010) Worldview transformation and the development of social consciousness. J Conscious Stud 17(7-1):18-36

Sharma M (2007) Personal to planetary transformation. Kosmos Journal. http://www.kosmosjournal.org/article/personal-to-planetarytransformation/
Sharma M (2017) Radical transformational leadership: strategic action for change agents. North Atlantic Books, Berkeley

Siegner A, Stapert N (2019) Climate change education in the humanities classroom: a case study of the Lowell school curriculum pilot. Environ Educ Res. https://doi.org/10.1080/13504622.2019.16072 58

Stengers I (2005) The cosmopolitical proposal. In: Latour B, Weibel P (eds) Making things public. MIT Press, Cambridge, pp 994-1003

Sterling S, Orr D (2001) Sustainable education: revisioning learning and change. UIT Cambridge Ltd., Cambridge

Stinson SW (1995) Body of knowledge. Educ Theory 45(1):43-54. https://doi.org/10.1111/j.1741-5446.1995.00043.x

Wang C, Burris MA (1997) Photovoice: concept, methodology, and use for participatory needs assessment. Health Educ Behav 24(3):369-387. https://doi.org/10.1177/109019819702400309

Weber A (2013) Enlivenment: towards a fundamental shift in the concepts of nature, culture and politics, 1st edn. Heinrich-Böll-Stift, Berlin

Wiebe S, Snowber C (2011) The visceral imagination: a fertile space for non-textual knowing. J Curric Theor 27(2)

Publisher's Note Springer Nature remains neutral with regard to jurisdictional claims in published maps and institutional affiliations. 